\title{
Morphometric Analysis of the Brain Ventricles in Normal Subjects Using Computerized Tomography
}

\author{
Moawia Gameraddin1,2*, Abdalrahim Alsayed1', Amir Ali3 ${ }^{3}$ Mosleh Al-Raddadi4 \\ ${ }^{1}$ Department of Diagnostic Radiologic, College of Medical Applied Sciences Technology, Taibah University, \\ Almadinah Al Munawwara, Kingdom of Saudi Arabia \\ ${ }^{2}$ Faculty of Radiological Sciences and Medical Imaging, Alzaiem Alazhari University, Khartoum, Sudan \\ ${ }^{3}$ Department of Anatomy, Faculty of Medicine, Taibah University, Almadinah Al Munawwara, Kingdom of Saudi \\ Arabia \\ ${ }^{4}$ Medical Imaging Department, King Fahad Hospital, Almadinah Al Munawwara, Kingdom of Saudi Arabia \\ Email: ${ }^{*}$ m.bushra@yahoo.com, a.alrahimtagelsir@yahoo.com, amirmoh.ali@gmail.com, drraddadi@yahoo.com
}

Received 9 February 2015; accepted 28 February 2015; published 3 March 2015

Copyright (C) 2015 by authors and Scientific Research Publishing Inc.

This work is licensed under the Creative Commons Attribution International License (CC BY).

http://creativecommons.org/licenses/by/4.0/

(c) (i) Open Access

\section{Abstract}

Background and Aim: As ageing advances, the human brain undergoes many gross and histopathological changes with regression of the brain tissue leading to the enlargement of the ventricles. Knowledge of morphometric and size of normal ventricular system of brain is important to understand these changes. Methods: For the present perspective study, computerized tomography (CT) for 152 patients (Males-89 and Females-63) were studied for the measurements of fourth ventricle, third ventricle and lateral ventricle and it was statistically analyzed. Results: The anteroposterior extent of the body of the lateral ventricles on the right side was $74.89+9.86 \mathrm{~mm}$ and $70.06+8.83 \mathrm{~mm}$ in the males and females and on the left side was $74.89+9.89 \mathrm{~mm}$ and $69.56+$ $11.42 \mathrm{~mm}$ in the males and females; the length of the frontal horns on the right side was $28.53+$ $3.88 \mathrm{~mm}$ and $26.16+4.21 \mathrm{~mm}$ in the males and females and on the left side was $28.53+3.88 \mathrm{~mm}$ and $26.17+4.237 \mathrm{~mm}$ in the males and females respectively. The width and height of the fourth ventricle were $12.54+1.90 \mathrm{~mm}$ and $9.66+2.12$ in the males and $11.60+2.099 \mathrm{~mm}$ and $9.70+$ 2.219 in the females respectively. The width of the third ventricle was $5.70+1.54 \mathrm{~mm}$ and $5.40+$ $1.68 \mathrm{~mm}$ in the males and females respectively. Conclusion: The present study has defined the morphometric measurements of the lateral ventricles, third ventricle, and fourth ventricle of the brain which has clinical correlations in diagnosis and for further line of treatment.

\section{Keywords}

Brain, Morphometry, Ventricular System, Size, Subjects, Tomography

\footnotetext{
${ }^{*}$ Corresponding author.

How to cite this paper: Gameraddin, M., Alsayed, A., Ali, A. and Al-Raddadi, M. (2015) Morphometric Analysis of the Brain Ventricles in Normal Subjects Using Computerized Tomography. Open Journal of Radiology, 5, 13-19. 


\section{Introduction}

The ventricular system of brain is cavity of brain. The two largest ventricles are the lateral ventricles in the cerebrum; the third ventricle is in the diencephalon of the forebrain between the right and left thalamus; and the fourth ventricle is located at the back of the pons and upper half of the medulla oblongata of the hindbrain [1].

Morphometric studies of human brain ventricles have been under focus by many scholars recently due to it is relation with pathologies evidences such as hydrocephalus, schizophrenia, tumors, Trauma... etc., as well as gender and aging which could lead to dementia and or brain geriatric [2] [3]. The advent of CT scanning resolved the problem of volumetric measurement performed on normal subjects [4]. The ventricles of the brain are well visualized, and their overall configuration can be reconstructed from a series of contiguous slices [5]. The evaluation of the normal measurements of the cerebral ventricles in the living human has great importance in the diagnosis and monitoring of several pathologies [6]. Accurate measurements of the ventricles provide available and safe means of aiding the diagnosis of some neurological disorders such as early detection of hydrocephalus, cerebral atrophy....etc, and provide important follow-up information in affected patients [7]. It should be noted that there is a continuous debate in the literature of neuro anatomy, psychiatry, neuroradiology and neurology over the best method of assessing the various parts of the cerebral ventricular system [8].

Little work has been done on measurement of cerebral ventricular system in Saudi Arabia. This present work is undertaken to study morphometric analysis of the lateral, third and fourth ventricles of the brain in normal Saudi subjects using CT scan.

\section{Materials and Methods}

\subsection{Selection and Description of Study Population}

This study has two designs and considered as a prospective cohort as well as retrospective with referring to the previous cases in the PACS system. The study population composed of 152 patients (89 males and 63 females) in the age group of 3 to 81 years, attending the department of Radiology, at King Fahd Hospital from the period of March to June 2014. The hospital was classified as one of the teaching hospital in Al medina Almunawwara. The radiology department (CT) receives about 15 cases per day (5475 cases per year). Informed consent was obtained from all patients for being included in the study and a previous ethical approval was obtained from the ethical committee of the hospital. The majority of the cases were selected from the PACS system and other cases were investigated directly with CT machine. There was no a Minimum Sample Size Calculation process before sampling.

These patients were selected randomly and clinically confirmed no history of cerebral infarction, local mass lesions, probable communicating hydrocephalus, alcoholism, drug abuse, trauma or previous intra-cranial surgery and other hereditary diseases and were not on medication at the time of this study. CT Scans of all patients were reported by expert radiologist scoring as normal. The CT scanner used in this study was the General electric GE (Bright speed 16 slices). The selected exposure factors were $120 \mathrm{kv}$ and $435 \mathrm{~mA}$, the slice thickness was ranged between 7 to $10 \mathrm{~mm}$ and the noise index was 3 .

\subsection{Procedure of CT Scanning Technique}

The patient was placed on the CT table and the head was centralized and supported for correct positioning and to avoid blurring of images. A lateral scout image was taken to confirm correct positioning of patient and appropriate exposure factors. Orbito-meatal line was drawn and a line at an angle of $15-20$ degrees to and $1 \mathrm{~cm}$ above it was drawn, representing the lowest tomographic section, which passed through the base of skull. A total of 8 to 10 axial image slices of the brain were obtained without any overlap.

\subsection{Method of Measuring the Brain Ventricle}

The lateral ventricles on CT are seen as two band-shaped structures with normal attenuation values. The third ventricle is amid-line structure which is shown between the thalami and the fourth ventricle is seen as an oval area at the center of the posterior fossa lower down, between the cerebellum and the pons. The measurements were taken as follows:

1) Level of Fourth Ventricle 
a) Greatest height of fourth ventricle in cm (Figure 1).

b) Greatest width of fourth ventricle in $\mathrm{cm}$ (Figure 1).

2) Level of Interventricular Foramen

a) Length of frontal horns of right lateral ventricle in Foramen (measured from its tip to the interventricular foramen).

b) Length of frontal horns of left lateral ventricle in $\mathrm{cm}$ (measured from its tip to the interventricular foramen) can be seen in Figure 2.

3) Lateral Ventricle Measurement:

a) Length of right lateral ventricular body inclusive of level of interventricular foramen. Frontal horn (taken from tip of frontal horn to the atrium).

b) Length of left lateral ventricular body inclusive of frontal horn (taken from tip of frontal horn to the atrium can be seen in Figure 3.

\subsection{Statistical Analysis}

Data were analyzed and initially summarized as mean \pm SD in a form of comparison tables. Statistical analysis was performed using the standard Statistical Package for the Social Sciences (SPSS Inc., Chicago, IL, USA) version 16 for windows. The statistical significant value was $5 \%$, values less than $5 \%$ were considered to be significant.

\subsection{Limitations}

One of the most limitations of this study, no volunteers conducted since x-rays has biological effects and hazards. There were many cases had been excluded from the study due to minor pathological changes in the brain which could influence the measurement? So, we tried as far as possible to find images with normal brain appearance.

\section{Results}

It was observed that the anteroposterior extent of the body of the right and left ventricles was equal in the males $(74.89+9.86 \mathrm{~mm})$ whereas, it was larger in the right side $(70.06+8.83 \mathrm{~mm})$ than the left side $(69.59+11.42$ $\mathrm{mm})$ in the females. It was also observed that mean length of the right frontal horns $(27.55+4.175 \mathrm{~mm})$ was

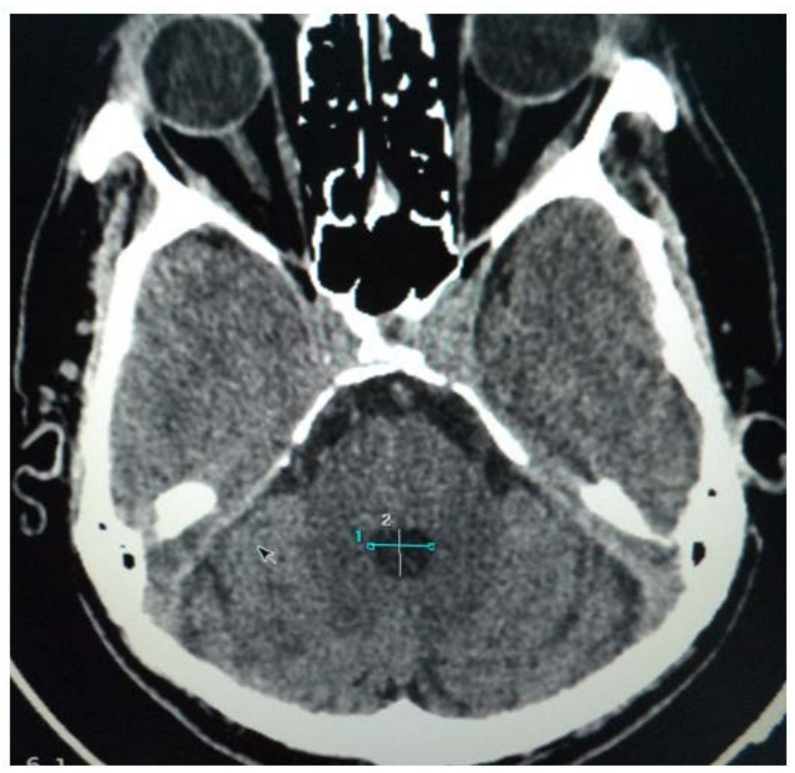

Figure 1. CT axial image of the brain showing the width and height measurement of the $4^{\text {th }}$ ventricle. The blue lines indicate the height and the width. 


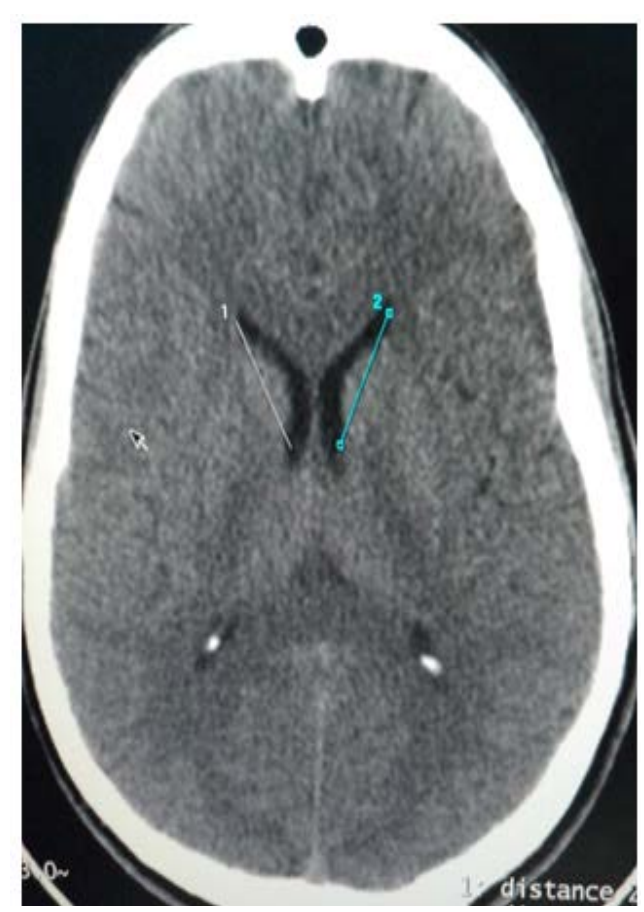

Figure 2. CT axial image of the brain showing the length of body of the lateral ventricles. The blue lines indicate the length of the body of both lateral ventricles.

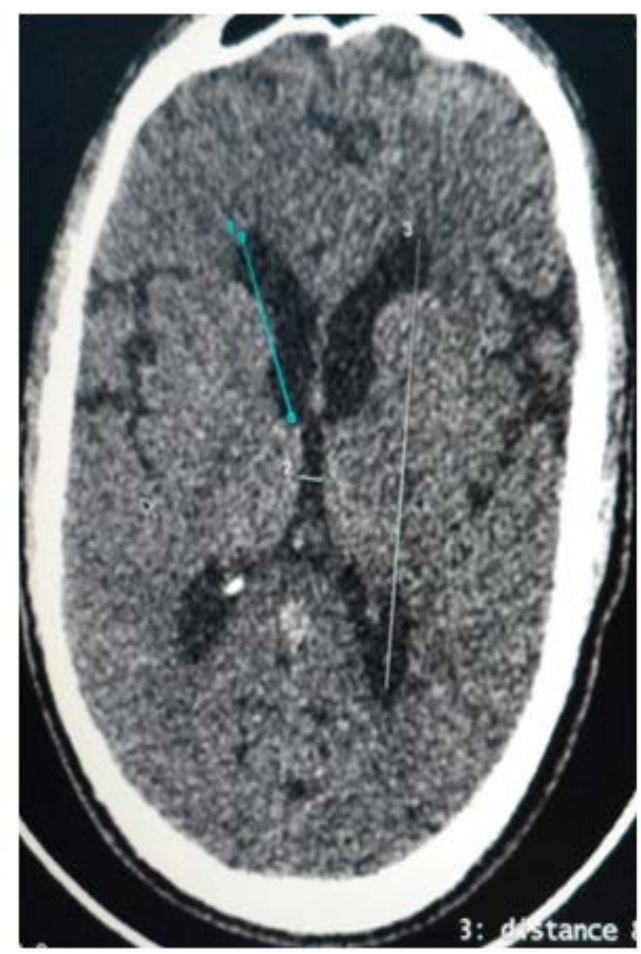

Figure 3. CT axial image of the brain showing the length of the left lateral ventricle and body of right ventricle. The three lines show the length of body of right ventricle, length of the whole left ventricle and width of the third ventricle respectively. 
equal to the mean length of the left frontal horns $(27.55+4.184 \mathrm{~mm})$ in males and females (Table 1$)$. It was observed that the length of the right and left horns were equal in the males $(28.53+3.88 \mathrm{~mm})$, and were greater than the females in the right $(26.16+4.209 \mathrm{~mm})$ and left $(26.17+4.237 \mathrm{~mm})$ as demonstrated in (Table 2). The mean height and width of the fourth ventricle was $9.68+2.155 \mathrm{~mm}$ and $12.15+2.032 \mathrm{~mm}$ in 152 subjects (males and females) as shown in (Table 1).

The width of fourth ventricle increases as age increases, which was statistically significant $(\mathrm{P}$-value $<0.05)$ as shown in (Table 3). The mean width of third ventricle was $5.57+1.60$ in 152 subjects (males and females).

The width of third ventricle increases as age increases, which was statistically significant $(\mathrm{P}$-value $<0.05)$ as shown in Table 1. The measurement of the ventricles was obtained from the CT monitor using the curser as demonstrated in Figures 1-3.

Table 1. Measurements and statistical details of lateral, third and fourth ventricles.

\begin{tabular}{|c|c|c|c|c|c|}
\hline \multirow[b]{2}{*}{ Table head } & \multicolumn{3}{|c|}{ Table column head } & \multirow[b]{2}{*}{$\begin{array}{l}\text { Mean } \\
(\mathrm{mm})\end{array}$} & \multirow[b]{2}{*}{ STD deviation } \\
\hline & Total & $\begin{array}{l}\text { Minimum } \\
(\mathrm{mm})\end{array}$ & $\begin{array}{l}\text { Maximum } \\
(\mathrm{mm})\end{array}$ & & \\
\hline $\begin{array}{l}\text { Length of body of the } \\
\text { right ventricle }\end{array}$ & 152 & 46 & 104 & 72.89 & 9.714 \\
\hline $\begin{array}{l}\text { Length of body of the } \\
\text { left ventricle }\end{array}$ & 152 & 9 & 104 & 72.68 & 10.823 \\
\hline $\begin{array}{l}\text { Length of right frontal } \\
\text { horn of Lateral ventricle }\end{array}$ & 152 & 15 & 37 & 27.55 & 4.175 \\
\hline $\begin{array}{l}\text { Length of left frontal } \\
\text { horn of lateral ventricle }\end{array}$ & 152 & 15 & 37 & 27.55 & 4.184 \\
\hline $\begin{array}{l}\text { Width of the } \\
\text { third ventricle }\end{array}$ & 152 & 3 & 11 & 5.57 & 1.601 \\
\hline $\begin{array}{l}\text { Height of the } \\
\text { fourth ventricle }\end{array}$ & 152 & 4 & 19 & 9.68 & 2.155 \\
\hline \multirow[t]{2}{*}{$\begin{array}{l}\text { Width of the } \\
\text { fourth ventricle }\end{array}$} & 152 & 8 & 18 & 12.15 & 2.032 \\
\hline & 152 & 46 & 104 & 72.89 & 9.714 \\
\hline
\end{tabular}

Table 2. Gender wise changes in the measurement and statistical details of the ventricular system.

\begin{tabular}{|c|c|c|c|c|c|}
\hline Measurement & Gender & \multicolumn{2}{|c|}{ Total mean } & Standard deviation & Significance p-value \\
\hline \multirow{2}{*}{ Length of body of the right ventricle } & Male & 89 & 74.89 & 9.860 & \multirow{2}{*}{0.002} \\
\hline & Female & 63 & 70.06 & 8.832 & \\
\hline \multirow{2}{*}{ Length of body of the left ventricle } & Male & 89 & 74.89 & 9.860 & \multirow{2}{*}{0.003} \\
\hline & Female & 63 & 69.56 & 11.420 & \\
\hline \multirow{2}{*}{ width of the third ventricle } & Male & 89 & 5.70 & 1.540 & \multirow{2}{*}{0.257} \\
\hline & Female & 63 & 5.40 & 1.680 & \\
\hline \multirow{2}{*}{$\begin{array}{l}\text { Length of right frontal } \\
\text { horn of Lateral ventricle }\end{array}$} & Male & 89 & 28.53 & 3.882 & \multirow{2}{*}{0.000} \\
\hline & Female & 63 & 26.16 & 4.209 & \\
\hline \multirow{2}{*}{$\begin{array}{l}\text { Length of left frontal horn of lateral } \\
\text { ventricle }\end{array}$} & Male & 89 & 28.53 & 3.882 & \multirow{2}{*}{0.001} \\
\hline & Female & 63 & 26.17 & 4.237 & \\
\hline \multirow{2}{*}{ Height of the fourth ventricle } & Male & 89 & 9.66 & 2.121 & \multirow{2}{*}{0.921} \\
\hline & Female & 63 & 9.70 & 2.219 & \\
\hline \multirow{2}{*}{ Width of the fourth ventricle } & Male & 89 & 12.54 & 1.901 & \multirow{2}{*}{0.005} \\
\hline & Female & 63 & 11.60 & 2.099 & \\
\hline
\end{tabular}


Table 3. Shows the correlation between age and width of the 4th and 3rd ventricles.

\begin{tabular}{ccc}
\hline & Age & \\
\hline Width of 4th ventricle & 0.410 & 0.000 \\
width of the third ventricle & 0.292 & 0.000 \\
\hline
\end{tabular}

\section{Discussion}

The range of changes in the ventricular size of the brain encountered in clinical practice can lead most people to believe that a decision taken without an exact measure of ventricular size, however, there is likely to be an increasing number of circumstances in which precise measurements will be of value.

Measurements of the size of the lateral cerebral ventricles provide useful indices of cerebral asymmetry and atrophy. The present study provides useful baseline measures on the volume of the lateral ventricle, and its variability and asymmetry, in healthy subjects, and promising first steps in the task of automatic measurement of the brain structure that is highly conspicuous but has relatively complex morphology.

According to Gomori et al., Takeda and Matsuzua, Goldestien et al. the left lateral ventricle was larger than the right one and both were larger in the female [9]-[11]. In our study the antero-posterior extent of the right ventricle bodies (males $=74.89+1.04 \mathrm{~mm}$ and females $=70.06+1.11 \mathrm{~mm}$ ) was approximately equals to the left ones (male $=74.89+1.04 \mathrm{~mm}$ and female $69.59+1.43 \mathrm{~mm}$ ). These measures are larger than the figures obtained by D'Souza and Natekar this may be due to the differences in age group that was larger in our study compared to D'Souza and Natekar study which was limited between 30 and 50 years [12].

Both left and right ventricles were large in males compared to females. This is because males have heavier and bigger skull, the capacity of the skull is $10 \%$ more compared to female skull and also because the brain size is more in males compared to females [13].

Our study results revealed that the length of the of the right frontal horns was $(28.53+0.41 \mathrm{~mm})$ in the males and $(26.16+0.53 \mathrm{~mm})$ in the females and that the length of the left frontal horns was equal to the right one in the males but slightly longer than the right one in the females $(26.17+0.53 \mathrm{~mm})$. This measures was much similar to the figures reported by D'Souza and Natekar (27.4 mm in the males and $25.5 \mathrm{~mm}$ in the females) for the right frontal horns and (27.8 $\mathrm{mm}$ in the males and 25.8 in the females) [12].

Studies by D'Souza and Natekar revealed that the height of the fourth ventricle was $11.8 \mathrm{~mm}$ and $11.1 \mathrm{~mm}$ for the male and female respectively. Older studies by Gawler et al. revealed that the greatest distance between the roof and the floor of the fourth ventricle was less than $10.8 \mathrm{~mm}$; however in our study this distance was significantly smaller, $(9.66+0.22 \mathrm{~mm})$ in males and $(9.70+0.28 \mathrm{~mm})$ in the females with the mean $9.68+0.17 \mathrm{~mm})$ [12] [14]. In the present study, the width of the fourth ventricle was found to be greater than the height in both genders and was more in males $(12.54+0.20 \mathrm{~mm})$ than in females $11.60+0.26 \mathrm{~mm})$ with the mean $(12.15+$ 0.16).

The width of third ventricle was measured by method of radiology by various workers like Gawler J et al., Soininen H et al., D’souza D. \& Natekar P., Meshram P. \& Hattangdi S., and Duffner F. et al. [14]-[16].

Brinkman et al., Soininen et al., D'Souza et al. and Vidya K et al. found that the maximum width of the third ventricle had a mean of $5.9 \mathrm{~mm}, 9.2 \mathrm{~mm}, 4.2 \mathrm{~mm}$ and $5.2 \mathrm{~mm}$. In our present study, we recorded this measure was significantly higher in males $(5.70 \mathrm{~mm})$ as compared to females (5.40 mm) with mean (5.57 mm) [15] [17][19].

Results of this study showed that there were statistically relationships between the ages of subjects involved in the study and the width of the third and fourth ventricles $(p=0.01)$ was in agreement with studies conducted by Vidya K. et al. and D’souza D. \& Natekar P. [12] [19].

\section{Conclusion}

The study provided useful morphometric data about the lateral, third and fourth ventricles while diagnosing visual disturbance, hydrocephalus, schizophrenia, psychotic disorders and other pathologies.

\section{Acknowledgements}

The authors would like to appreciate the role of staff of the Radiology Department at King Fahd Hospital for 
their cooperation, help and support during data collection.

\section{References}

[1] Singh, V. (2010) Textbook of Clinical Neuroanatomy. Elsevier, 120-123, 137.

[2] Haslam, R.H. (1992) Hydrocephalous. In: Behrman, R.E, Kliegman, R.M., Nelson, W.E. and Vaughan, V.C., Eds., Nelson Text Book of Pediatrics, 14th Edition, W.B. Saunders Co., Philadelphia, 1487.

[3] Soni, J.P., B.D., Gupta, M., Soni, R.N., Singh, N.N., Purohit, M., Gupta, D.R. and Dabi, N. (1994) Normal Parameters of Ventricular System in Healthy Infants. Indian Pediatric, 32, 549-555.

[4] Hounsfield, G.N. (1973) Computerized Transverse Axial Scanning (Tomography): Part 1. Description of System. The British Journal of Radiology, 46, 1016-1012. http://dx.doi.org/10.1259/0007-1285-46-552-1016 http://www.birpublications.org/doi/abs/10.1259/0007-1285-46-552-1016

[5] Penn, R.D., Belanger W.G. and Yasnoff, W.A. (1978) Ventricular Volume in Man Computed from CAT Scans. Annals of Neurology, 3, 316-323. http://dx.org/doi/10.1002/ana.410030306/abstract.

[6] Sabattini, L. (1982) Evaluation and Measurement of the Normal Ventricular and Subarachnoid Spaces by CT. Neuroradiology, 23, 1-5. http://dx.doi.org/10.1007/BF00399698 http://link.springer.com/article/10.1007\%2FBF00399698

[7] Delsi, L.E., Perman, G.P., Targus, S.D. and Wyatt, R.J. (1982) CT in Chronic Schizophrenia Form Disorder and Other Acute Psychiatric Disorders. Archives of General Psychiatry, 39, 778-783. http://dx.doi.org/10.1001/archpsyc.1982.04290070014004

[8] Gyldensted, C. and Kosteljanetz, M. (1977) Measurements of the Normal Ventricular System and Hemispheric Sulci of 100 Adult Patients with Computed Tomography. Neuroradiology, 14, 138-192. http://dx.doi.org/10.1007/BF00496982 http://link.springer.com/article/10.1007\%2FBF00496982

[9] Gomori, J.M., Steiner, I. and Meland, E. (1984) The Assessment of Changes in Brain Volume Using Combined Linear Measurements. A CT Study. Neuroradiology, 26, 21-24. http://dx.doi.org/10.1007/BF00328197 http://link.springer.com/article/10.1007\%2FBF00328197

[10] Takeda, S. and Matsuzua, T. (1985) Age-Related Changes in Volumes of the Ventricles, Cisternae and Sulci: A Quantitative Study Using CT. Journal of the American Geriatrics Society, 33, 264-268.

[11] Goldstien, J.M., Seidman, L.J., Horton, N.J., Markis, N., Kenneky, D.N., Caviness, V.S., Faraone, S.V. and Tsuang, M.T. (2001) Normal Sexual Dimorphism of the Adult Human Brain Assessed by in Vivo Magnetic Resonance Imaging. Cerebral Cortex, 11, 490-497. http://dx.doi.org/10.1093/cercor/11.6.490

[12] D’Souzae, D.M. and Natekar, P.E. (2007) Morphometric Study of the Ventricular System of Brain by Computerized Tomography. Journal of the Anatomical Society of India, 56, 19-24.

[13] Williams, P.L., Bannister, L.H., Berry, M.M., Collins, P., Dyson, M. and Dussek, J.M. (1995) Gray’s Anatomy: The Anatomical Basis of Medicine and Surgery. 38th Edition, Elsevier Churchill Livingstone, Edinburgh, 1205-1209.

[14] Gawler, J., Du Boulay, G.H., Bull, J.W. and Marshall, J. (1976) Computerized Tomography the (EMI Scanner): A Comparison with Pneumoencephalography and Ventriculography. Journal of Neurology, Neurosurgery, \& Psychiatry, 39, 203-211. http://dx.doi.org/10.1136/jnnp.39.3.203

[15] Soininen, H., Puramen, M. and Riekkinen, P.J. (1982) Computed Tomography Findings in Senile Dementia and Normal Ageing. Journal of Neurology, Neurosurgery, \& Psychiatry, 45, 50-54. http://dx.doi.org/10.1136/jnnp.45.1.50

[16] Meshram, P. and Hattangdi, S. (2012) The Morphometric Study of Third Ventricle and Diencephalon by Computerized Tomography. Indian Journal of Applied Basic Medical Science, 14, 8-13.

[17] Duffner, F., Schiffbauer, H., Glemser, D., Skalej, M. and Freudenstein, D. (2003) Anatomy of the Cerebral Ventricular System for Endoscopic Neurosurgery: A Magnetic Resonance Study. Acta Neurochirurgica, 145, 359-368.

[18] Brinkman, S.D., Sarwar, M., Levin, H. and Morris, H.H. (1981) Quantitative Indices of Computed Tomography in Dementia and Normal Ageing. Radiology, 138, 89-92. http://dx.doi.org/10.1148/radiology.138.1.7455102

[19] Vidya, K., Mital, M., Patel, J., Rathava, P., Trivedi, U., Kukadiya, D., Dilip, V. and Tulsibhai, C. (2014) Morphometry of Width of Third Ventricle of Brain by Luminal Cast Plastination. International Journal of Advanced Research, 2, 837-842. http://www.scopemed.org/10.5455/jrmds.20142211 